Abstracta Iranica Abstracta Iranica

Revue bibliographique pour le domaine irano-aryen

Volume 31 | 2011

Comptes rendus des publications de 2008

\title{
Ashkelon 1. Introduction and Overview (1985-2006). Eisenbrauns, 2008, 708 p.
}

\section{Astrid Nunn}

\section{(2) OpenEdition}

1 Journals

\section{Édition électronique}

URL : http://journals.openedition.org/abstractairanica/39450

DOI : 10.4000/abstractairanica.39450

ISSN : 1961-960X

Éditeur :

CNRS (UMR 7528 Mondes iraniens et indiens), Éditions de l'IFRI

\section{Édition imprimée}

Date de publication : 15 mai 2011

ISSN : 0240-8910

\section{Référence électronique}

Astrid Nunn, «Ashkelon 1. Introduction and Overview (1985-2006). Eisenbrauns, 2008, 708 p. », Abstracta Iranica [En ligne], Volume 31 | 2011, document 68, mis en ligne le 11 octobre 2012, consulté le 05 octobre 2020. URL : http://journals.openedition.org/abstractairanica/39450 ; DOI : https://doi.org/ 10.4000/abstractairanica.39450

Ce document a été généré automatiquement le 5 octobre 2020.

Tous droits réservés 


\title{
Ashkelon 1. Introduction and Overview (1985-2006). Eisenbrauns, 2008, 708 p.
}

\author{
Astrid Nunn
}

Ce volume étant le premier de 10 planifiés, il donne au lecteur un aperçu général du site majeur d'Ashkelon. Les prospections sont très diverses et vont de l'environnement terrestre et des surveys sous-marins au travail archéologique sur le site lui-même. Ce site, qui subsista d'environ 2000 av. J.-C. à l'époque mamelouke, fut détruit en 604 av. J.C. et resta abandonné un siècle. La vie reprend à l'époque achéménide. Les couches XI (env. 525-450 av. J.-C.), X (env. 450-400 av. J.-C.), IX (env. 400-350 av. J.-C.) et VIII (env. 350-290 av. J.-C.) datent de cette époque. L'architecture achéménide consiste en maisons, dans lesquelles se trouvait surtout de la céramique. Quelque peu énigmatiques sont les ensevelissements de chiens. Ce chapitre de Paula Wapnish et Brian Hesse, «The Ashkelon Dog Burials: Data and Interpretations » (p. 541-564) est une reprise actualisée de l'article dans BA 56/2, 1993 (p. 55-80). 1238 chiens ont été ensevelis dans le tell du sud ("South Tell"), dont 970 à l'époque achéménide. 565 entre eux sont des chiots (de 0-6 mois), 351 sont des adultes de plus de 18 mois et 54 sont à situer entre ces deux âges. Ils sont morts naturellement. Les AA. passent en revue les cimetières de chiens au Proche Orient ancien. Il aurait fallu être plus prudents et ne pas écrire: «No dog remains are reported from Phoenician settlements outside of Ashkelon (and possibly Dor)» (p. 563). Car, même sans vouloir être exhaustifs, les AA. auraient dû citer les deux sites phéniciens de Beyrouth et Tell Burak. La tombe de Tell Burak se trouvait dans une maison et remonte à la fin de l'âge du Fer (J. Kamlah - H. Sader, « The Tell el-Burak Archaeological Project. Preliminary Report on the 2002 and 2003 Seasons ", BAAL $7,2003,149)$ et une dizaine de tombes canines d'époque achéménide furent découvertes aus dessus du glacis à Beyrouth (U. Finkbeiner - H. Sader, «Bey 020: Preliminary Report of the Excavations 1995 ", BAAL 2, 1997, 130-132 et Abs. Ir. 20-21, 1997-1998, c.r. n¹56). Les sépultures de Beyrouth sont évidemment infiniment moins nombreuses qu'à Ashkelon, mais les modes d'ensevelissement sont tout à fait comparables. La véritable signification de ce rite nous échappe encore. Des Inscriptions que F. M. Cross, «Inscriptions in Phoenician and Other Scripts », (p. 333-372) présente, deux sont phéniciennes et datent de l'époque achéménide (p. 350-365). Achéménides 
sont également 6 ostraca, 10 fragments d'amphore et 9 fragments de céramique attique à vernis noir sur lesquels apparaît un nom de personne. Un trésor de 31 oboles du type d'Athéna à la chouette, dont certaines font partie de la série d'imitation philisto-arabe, est traité par H. Gitler, "Coins of the Fifth and Fourth Centuries B.C.", p. 373-384 (réimpression de NC 156, 1996, 1-9). H. Gitler rassemble 12 autres monnaies des environs (marché des Antiquités, collections privées ou musées) au même motif. Tristan Barako, «Amphoras Through the Ages », (p. 429-461) enfin, nous offre un tour de l'histoire des amphores du Bronze Moyen aux Mameloukes. Des 31 types d'amphore, les $n^{\circ} 18$ et 19 sont perses et les n²0-24 perses-tardif-hellénistiques.

INDEX

Thèmes : 3.2.2. Pré-Achéménides et Achéménides

\section{AUTEURS}

\section{ASTRID NUNN}

Université de Munich 